\title{
In vitro and in vivo susceptibility of the honeybee bacterial pathogen Paenibacillus larvae subsp. larvae to the antibiotic tylosin
}

\author{
Adriana M. Alippi ${ }^{\text {a,* }}$, Graciela N. Albo ${ }^{\text {}}$, Francisco J. Reynaldi ${ }^{\text {a }}$, \\ Marisa R. De Giusti ${ }^{\mathrm{c}}$ \\ ${ }^{a}$ Centro de Investigaciones de Fitopatología, Facultad de Ciencias Agrarias y Forestales, \\ Universidad Nacional de La Plata, c.c. 31, calles 60 y 118, 1900 La Plata, Argentina \\ ${ }^{\mathrm{b}}$ Curso de Zootecnia AMG, Facultad de Ciencias Agrarias y Forestales, \\ Universidad Nacional de La Plata, 1900 La Plata, Argentina \\ ${ }^{\mathrm{c}}$ PREBI - ISTEC, Facultad de Ingeniería, Universidad Nacional de La Plata, 1900 La Plata, Argentina
}

Received 26 November 2004; received in revised form 2 March 2005; accepted 2 March 2005

\begin{abstract}
The minimal inhibitory concentrations (MICs) of tylosin were determined to 67 strains of Paenibacillus larvae subsp. larvae, the causal agent of American Foulbrood (AFB) disease, from different geographical origins. MIC values obtained ranged from 0.0078 to $0.5 \mu \mathrm{g} / \mathrm{ml}$. These very low values imply that no resistance to tylosin was found in any isolate of the Foulbrood pathogen.

The measurement of diseased larvae with AFB-clinical symptoms in three different field studies demonstrated that tylosin treatment could be effective in vivo. No negative effects in colonies were noted at any dosage rates or forms of application. These studies demonstrate that tylosin, as tartrate, can be used to treat AFB in honeybee colonies.
\end{abstract}

(C) 2005 Elsevier B.V. All rights reserved.

Keywords: American Foulbrood; Tylosin; Paenibacillus larvae subsp. larvae

\section{Introduction}

American Foulbrood (AFB) disease caused by the spore-forming bacterium Paenibacillus larvae subsp. larvae (P.l. larvae) (Heyndrickx et al., 1996) (formerly

\footnotetext{
* Corresponding author. Tel.: +54 2214271341 ; fax: +54221 4252346 .

E-mail address: amalippi@netverk.com.ar (A.M. Alippi).
}

Bacillus larvae) is a cosmopolitan disease of bacterial origin affecting the larval and pupal stages of honeybees (Apis mellifera L.) (White, 1920; Shimanuki, 1990). Diseased individuals turn brown, then black, and the resultant mass becoming a hard scale of material deposited on the side of the cell. AFB is one of the few bee diseases capable of killing a colony, and has unique problems for prevention and control because the spores can remain viable for long periods 
of time and survive environmental adversities (Matheson and Reid, 1992). The disease is highly contagious and if undetected can kill a colony and spread to others within the same apiary or to another apiary nearby by robbing and exchanging of brood combs, the main sources of contamination.

In areas where disease incidence is high, antibiotic treatments appear as an alternative to the burning of diseased bee colonies. Currently, the only antibiotic approved for prevention and control of AFB is oxytetracycline, however, there is evidence of oxytetracycline-resistant isolates of P.l. larvae in certain areas of the USA, Canada and Argentina (Alippi, 2000; Colter, 2000; Evans, 2003; Miyagi et al., 2000).

The antibiotic tylosin, as tartrate, has been shown to be an alternative to oxytetracycline for the control of AFB in several studies (Alippi et al., 1999; Elzen et al., 2002a,b; Hitchcock et al., 1970; Moffett et al., 1970; Peng et al., 1996). Tylosin is virtually non-toxic to adult honeybees (Alippi et al., 1999) and less toxic than oxytetracycline to honeybee larvae (Peng et al., 1992, 1996).

The purposes of the present work were to evaluate the susceptibility of 67 strains of P.l. larvae from diverse geographical areas to tylosin by determining their minimal inhibitory concentrations (MIC), since the information about their efficacy in vitro is quite limited (Alippi, 1994; Kochanski et al., 2001; Okayama et al., 1996) and to determine the response of colonies with clinical signs of AFB to tylosin at different doses and forms of application in order to determine the most effective dose for disease control and lack of recurrence of the disease.

\section{Materials and methods}

\subsection{Bacterial strains}

The 67 P.l. larvae strains from diverse geographical origins used in this study are listed in Table 1. For the isolation of P.l. larvae strains from larvae affected by AFB and from honey samples, previously described techniques were employed (Alippi, 1995; Alippi and Aguilar, 1998; Alippi et al., 2004). In addition, reference strains from culture collections were included, and also strains of Pseudomonas aeruginosa, Escherichia coli and Staphylococcus aureus used as reference standards for quality control ranges of MICs were provided by Instituto Malbrán Collection, Instituto Malbrán, Buenos Aires, Argentina (Table 1).

\subsection{Determination of minimal inhibitory concentrations of tylosin}

As there is no NCCLS recommendation for the determination of MICs of P.l. larvae, a method developed for this species was used based on the NCCLS standard for Bacteria isolated from animals (NCCLS, 1999). Minimal inhibitory concentrations of tylosin tartrate $\left(\operatorname{Sigma}{ }^{\mathbb{R}}\right.$ ) were determined by the agar dilution method using MYPGP (Dingman and Stahly, 1983) as basal medium because P.l. larvae is not able to growth on Muller-Hinton agar. Tylosin concentrations tested were made using a stock solution of $5000 \mu \mathrm{g} / \mathrm{ml}$ in distilled water and sterilized using a syringe-driven filter unit with a $0.22 \mu \mathrm{m}$ pore size. Appropriate dilutions were made in sterile distilled water and stored at $-20{ }^{\circ} \mathrm{C}$ until used. The medium was maintained at $45^{\circ} \mathrm{C}$ until the antibiotic solutions were incorporated and $25 \mathrm{ml}$ of culture medium were poured onto each Petri plate of $90 \mathrm{~mm}$ in diameter. Increasing concentrations of tylosin tested were: $0.0039,0.0078,0.015$, $0.03125,0.0625,0.125,0.5,1,2,4,8,16$ and $32 \mu \mathrm{g} / \mathrm{ml}$ of medium. For the controls, MYPGP agar without antibiotic was employed.

Vegetative cells of each P.l. larvae strain grown on MYPGP agar for $48 \mathrm{~h}$ of incubation at $37^{\circ} \mathrm{C}$ were suspended in sterile distilled water and adjusted to approximately $2.87 \times 10^{8}$ cells $/ \mathrm{ml}\left(A_{620 \mathrm{~nm}}=0.388\right.$, equivalent to a Mc Farland standard of 1). The different bacterial strains were layered by using an automatic micropipette to place drops of $10 \mu \mathrm{l}$ each over the surface of the solidified culture medium containing each antibiotic concentration. Ten replications were tested for each strain. The inoculated plates were examined for growth after $48 \mathrm{~h}$ of incubation at $37^{\circ} \mathrm{C}$. The lowest concentration of antibiotic preventing growth was defined as the MIC (complete inhibition of bacterial growth on the test plates, disregarding a single colony of faint haze caused by inoculum).

In the case of $P$. aeruginosa, E. coli and $S$. aureus used as reference standards, the technique outlined by the NCCLS for each species (NCCLS, 1999) was followed, with the only difference that MYPGP agar was used as basal medium. 
Table 1

Minimal inhibitory concentration values (MICs) $(\mu \mathrm{g} / \mathrm{ml})$ for selected isolates and designation and origin of the bacterial strains used in this study

\begin{tabular}{|c|c|c|c|c|c|}
\hline Strain & Other designation & Geographical origin & Source & Year & MIC \\
\hline \multicolumn{6}{|c|}{ Paenibacillus larvae subsp. larvae } \\
\hline PL3 & & Concordia, Entre Ríos, Argentina ${ }^{a}$ & Diseased larvae & 1992 & 0.0625 \\
\hline PL7 & & Pigüe, Buenos Aires, Argentina ${ }^{a}$ & Diseased larvae & 1992 & 0.125 \\
\hline PL14 & & San Martín, La Pampa, Argentina ${ }^{a}$ & Diseased larvae & 1995 & 0.0625 \\
\hline PL15 & & La Plata, Buenos Aires, Argentina ${ }^{a}$ & Diseased larvae & 1995 & 0.0625 \\
\hline PL21 & & New Zealand ${ }^{\mathrm{b}}$ & Diseased larvae & 1995 & 0.03125 \\
\hline PL25 & & New Zealand ${ }^{\mathrm{b}}$ & Diseased larvae & 1995 & 0.125 \\
\hline PL30 & & New Zealand ${ }^{\mathrm{b}}$ & Diseased larvae & 1995 & 0.03125 \\
\hline PL32 & & Arroyo Alegre, Córdoba, Argentina ${ }^{a}$ & Diseased larvae & 1995 & 0.03125 \\
\hline PL33 & & Cháscomus, Buenos Aires, Argentina ${ }^{a}$ & Diseased larvae & 1995 & 0.5 \\
\hline PL34 & & Valle Medio, Rio Negro, Argentina $^{a}$ & Diseased larvae & 1995 & 0.0625 \\
\hline PL35 & & Chimpay, Rio Negro, Argentina ${ }^{a}$ & Diseased larvae & 1995 & 0.125 \\
\hline PL41 & & Lecce, Italy ${ }^{\mathrm{c}}$ & Diseased larvae & 1991 & 0.125 \\
\hline PL42 & & Modena, Italy ${ }^{c}$ & Diseased larvae & 1992 & 0.015 \\
\hline PL44 & & Padova, Italy ${ }^{\mathrm{c}}$ & Diseased larvae & 1995 & 0.25 \\
\hline PL45 & & Vanchuse, France $^{\mathrm{d}}$ & Diseased larvae & 1995 & 0.03125 \\
\hline PL49 & & Var, France ${ }^{\mathrm{d}}$ & Diseased larvae & 1995 & 0.0625 \\
\hline PL51 & & Lincoln, Buenos Aires, Argentina ${ }^{a}$ & Diseased larvae & 1995 & 0.5 \\
\hline PL57 & & Uppsala, Sweden ${ }^{\mathrm{e}}$ & Diseased larvae & 1995 & 0.125 \\
\hline PL58 & & Uppsala, Sweden $^{\mathrm{e}}$ & Diseased larvae & 1995 & 0.03125 \\
\hline PL59 & & Uppsala, Sweden $^{\mathrm{e}}$ & Diseased larvae & 1995 & 0.015 \\
\hline PL64 & & Ranchos, Buenos Aires, Argentina ${ }^{a}$ & Honey & 1995 & 0.5 \\
\hline PL71 & & Grye, Poland ${ }^{\mathrm{f}}$ & Received as a culture & 1996 & 0.25 \\
\hline PL73 & & Skierne, Poland ${ }^{\mathrm{f}}$ & Received as a culture & 1996 & 0.125 \\
\hline PL74 & CCM 4483 & Czech Republic ${ }^{g}$ & Culture & - & 0.03125 \\
\hline PL76 & CCM 4485 & Czech Republic ${ }^{\mathrm{g}}$ & Culture & - & 0.125 \\
\hline PL78 & & Argentina $^{\mathrm{a}}$ & Honey & 1996 & 0.125 \\
\hline PL81 & & Dufaur, Buenos Aires, Argentina $^{a}$ & Diseased larvae & 1996 & 0.0625 \\
\hline PL85 & & New York, USA ${ }^{\mathrm{h}}$ & Diseased larvae & 1996 & 0.0625 \\
\hline PL89 & & Holzkirchen, Germany ${ }^{\mathrm{i}}$ & Diseased larvae & 1994 & 0.0625 \\
\hline PL90 & & Holzkirchen, Germany ${ }^{\mathrm{i}}$ & Diseased larvae & 1994 & 0.125 \\
\hline PL91 & & Holzkirchen, Germany ${ }^{\mathrm{i}}$ & Diseased larvae & 1994 & 0.03125 \\
\hline PL95 & & Devon, $\mathrm{UK}^{\mathrm{j}}$ & Received as a culture & 1997 & 0.25 \\
\hline PL96 & & Leicester, $\mathrm{UK}^{\mathrm{j}}$ & Received as a culture & 1997 & 0.125 \\
\hline PL97 & & Kent, $\mathrm{UK}^{\mathrm{j}}$ & Received as a culture & 1997 & 0.0625 \\
\hline PL99 & & Argentina $^{a}$ & Commercial honey & 1997 & 0.125 \\
\hline PL100 & & Tunicia $^{\mathrm{a}}$ & Honey & 1997 & 0.125 \\
\hline PL101 & ATCC 9454 & $\mathrm{USA}^{\mathrm{k}}$ & Received as a culture & - & 0.125 \\
\hline PL102 & & Argentina $^{a}$ & Commercial honey & 1998 & 0.5 \\
\hline PL103 & NRRL B 3555 & $\mathrm{USA}^{1}$ & Received as a culture & - & 0.125 \\
\hline PL104 & ATCC 2574 & $\mathrm{USA}^{\mathrm{k}}$ & Received as a culture & - & 0.03125 \\
\hline PL155 & & Magdalena, Buenos Aires, Argentina ${ }^{a}$ & Honey & 1999 & 0.0625 \\
\hline PL202 & & Italy $^{\mathrm{a}}$ & Commercial honey & 1999 & 0.5 \\
\hline PL206 & & Gral. Pinto, Buenos Aires, Argentina ${ }^{a}$ & Honey & 1999 & 0.25 \\
\hline PL212 & & Toronto, Canada ${ }^{a}$ & Commercial honey & 1999 & 0.125 \\
\hline PL213 & & Toronto, Canada ${ }^{\mathrm{a}}$ & Commercial honey & 1999 & 0.25 \\
\hline PL214 & & Toronto, Canada ${ }^{\mathrm{a}}$ & Commercial honey & 1999 & 0.125 \\
\hline PL231 & & France $^{\mathrm{a}}$ & Commercial honey & 1999 & 0.0625 \\
\hline PL238 & & France $^{a}$ & Commercial honey & 1999 & 0.25 \\
\hline PL252 & & Spain $^{\mathrm{m}}$ & Received as a culture & 2000 & 0.125 \\
\hline PL255 & & Spain $^{\mathrm{m}}$ & Received as a culture & 2000 & 0.0625 \\
\hline PL284 & & Nueva Palmira, Uruguay ${ }^{\mathrm{n}}$ & Received as a culture & 2000 & 0.03125 \\
\hline PL286 & & Paysandú, Uruguay ${ }^{\mathrm{n}}$ & Received as a culture & 2000 & 0.03125 \\
\hline
\end{tabular}


Table 1 (Continued)

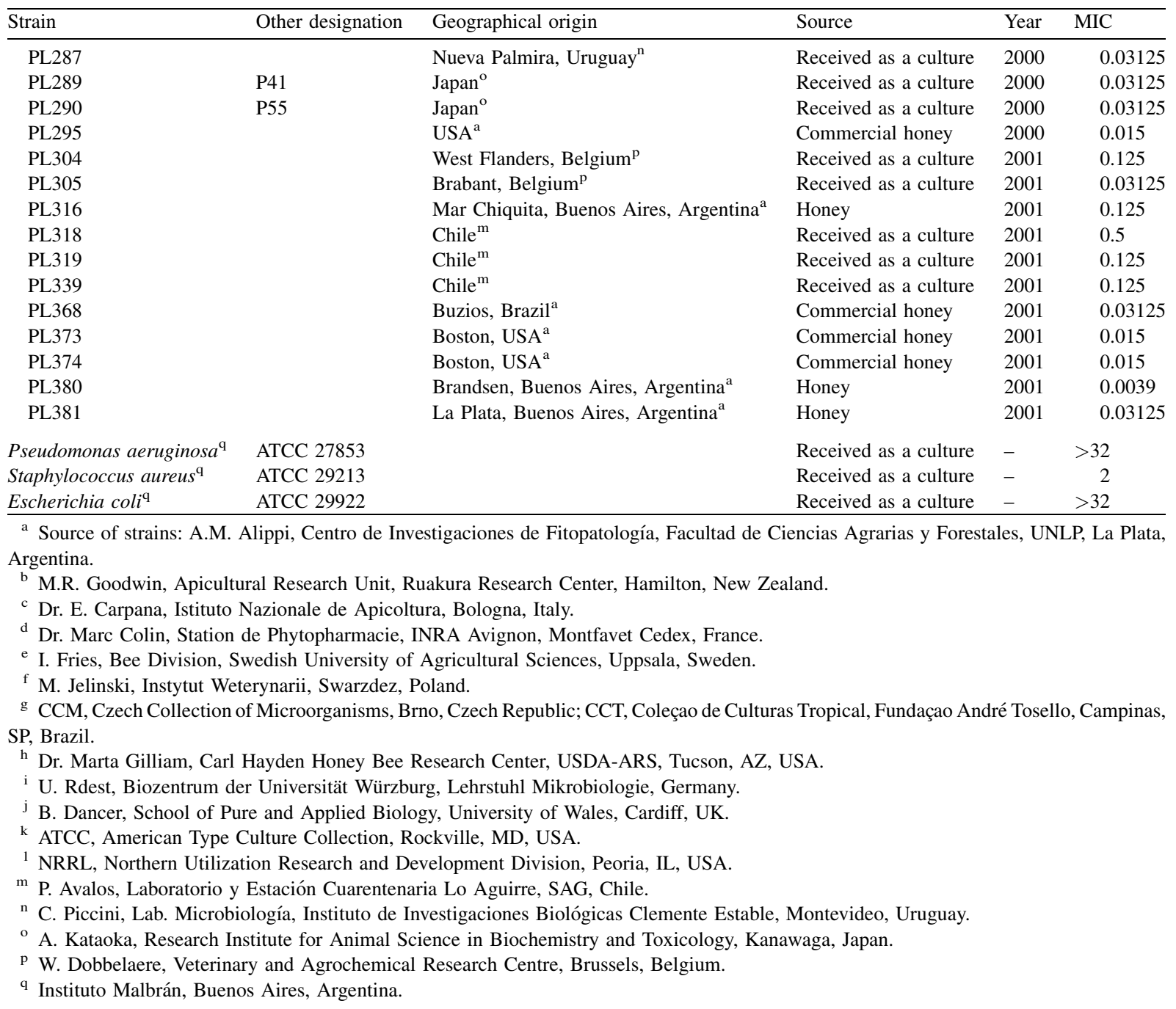

\subsection{Field experiments}

The efficiency of tylosin tartrate for the control of AFB on diseased bee colonies was evaluated on three field experiments conducted at the Faculty of Agricultural Science Experimental Field, UNLP, La Plata $35^{\circ} \mathrm{S}$ latitude, $57^{\circ} \mathrm{W}$ longitude. In all experiments, colonies of honeybees derived from Apis mellifera ligustica $\mathrm{L}$. were used. Queens were marked and their wings were clipped to avoid swarming. Colonies were distributed in a completely randomized design. The experimental procedures for inoculation were conducted as described by Alippi et al. (1999).
The amount of healthy brood, adult bees and larvae with AFB-clinical symptoms were measured in the same way in all of the experiments. Healthy brood cells (larvae and pupae) were quantified according to the following scale: grade 0 , absence of brood cells; grade 0.5 , between 1 and 499 brood cells; grade 1 , between 500 and 3499 brood cells; grade 2, between 4000 and 7999 brood cells; grade 3, between 8000 and 11,499 brood cells; grade 4, between 12,000 and 15,999 brood cells and grade 5, between 16,000 and more than 16,000. The number of adult bees were quantified in a similar manner, with a minimum of grade 0 and a maximum grade 5 , being grade 0 , 
absence of adult bees and grade 5, 16,000 or more than 16,000 bees per colony. Measurement of clinical signs of AFB were estimated according to a seven levels scale, where level 0 is non-detectable AFB symptoms; level 1, between 1 and 10 larvae with clinical signs of AFB; level 2, between 11 and 30 larvae with clinical signs of AFB; level 3, between 31 and 99 larvae with clinical signs of AFB; level 4, more than 100 larvae with clinical signs of AFB; level 5, Queen supersedure due to AFB and level 6, colony death, respectively.

The first experiment started in March and ended in October 2000. The 10 colonies used were from packs graded 4 for bees, 3 for brood and 0 for AFB-infection. Two treatments with five repetitions each were applied: five colonies were treated with $1.5 \mathrm{~g}$ of tylosin tartrate (Tylan Esanco ${ }^{\mathbb{R}}$ ) and five colonies were used as AFB-inoculated controls. The total dose ( $1.5 \mathrm{~g}$ per colony) was divided in six parts preparing $70 \mathrm{~g}$ candies (55 g powdered sugar $+15 \mathrm{~g} \mathrm{55 \%} \mathrm{sugar}$ syrup $+0.25 \mathrm{~g}$ active ingredient (a.i. of tylosin tartrate); cherry jelly was used as an attractant to ensure consumption. For controls a mixture of powdered sugar, sugar syrup and cherry jelly was used. The first candy was supplied as preventive 15 days before the inoculations of colonies with AFBcontaminated combs containing $20 \pm 5$ scales (Alippi et al., 1999). Inoculated colonies were evaluated once a month starting 30 days after inoculation. Each candy was replaced with a new one every 2 weeks. At the end of the experiment disease recurrence was also evaluated.

The second experiment was carried out between April and August 2001. The 10 colonies used were from packs graded 4 for bees, 3 for brood and 0 for AFB disease signs. Inoculations and evaluation of colonies were managed like those in the first experiment, but with modifications in doses and form of administration of the antibiotic. Two treatments with five repetitions each were applied: five colonies were treated with $0.750 \mathrm{~g}$ tylosin tartrate in a $70 \mathrm{~g}$ candy 15 days before inoculation and five colonies used as AFB-inoculated controls were supplied with a $70 \mathrm{~g}$ candy. Four monthly inspections were made starting 30 days after infection.

The third experiment took place between May and October 2002. Twelve colonies were used and were graded 4 for bees, 3 for brood and 0 for AFB-infection. The differences with the former experiment were: the treatments were applied by means of monthly supplied syrup. Six colonies were treated with $0.750 \mathrm{~g}$ tylosin tartrate and six colonies were used as AFB-inoculated controls (50\% sacarose syrup). The total dose of tylosin for the first group was provided at the first application with $750 \mathrm{cc}$ of syrup 30 days after infection. Four monthly applications of 50\% syrup without antibiotic were made afterwards. Controls were supplied in five monthly applications consisting of $750 \mathrm{cc} 50 \%$ sacarose syrup. Taste was improved by adding $0.5 \mathrm{ml}$ raspberry essence to each jar.

\subsection{Statistical analysis}

Wilcoxon two-sample test was used for analyzed significant differences $(p<0.05)$ between colonies treated with tylosin and untreated controls in each experiment as described by Spivak and Reuter (2001). Mantel Haenszel Chi-square test and also Fisher exact test (two tails), specially suited for small samples, were run in order to estimate the infection among treatments $(p<0.05)$ in all three experiments. In the same way, the Fisher exact test was used to estimate significant differences in the number of brood cells and that of adult bees between tylosin treatments and AFB-inoculated controls. Results from all three experiments were combined for that purpose (Spivak and Reuter, 2001).

\section{Results and discussion}

\subsection{Minimum inhibitory concentrations of tylosin}

MYPGP probed adequate for growth and interpretation of MIC values of P.l. larvae and also results for $P$. aeruginosa, E. coli and $S$. aureus are within the acceptable limits for quality control strains (NCCLS, 1999). All P.l. larvae strains were highly susceptible to tylosin with MIC values ranging from 0.0078 to $0.5 \mu \mathrm{g} / \mathrm{ml}$ depending upon the tested strain (Fig. 1). Results are summarized in Table 1. These values indicate that very low concentrations of tylosin are required to inhibit the growth of P.l. larvae. The appearance of oxytetracycline-resistant P.l. larvae strains in many countries has given a high priority to the search of alternatives being tylosin highly effective for the control of the Foulbrood pathogen in vitro 


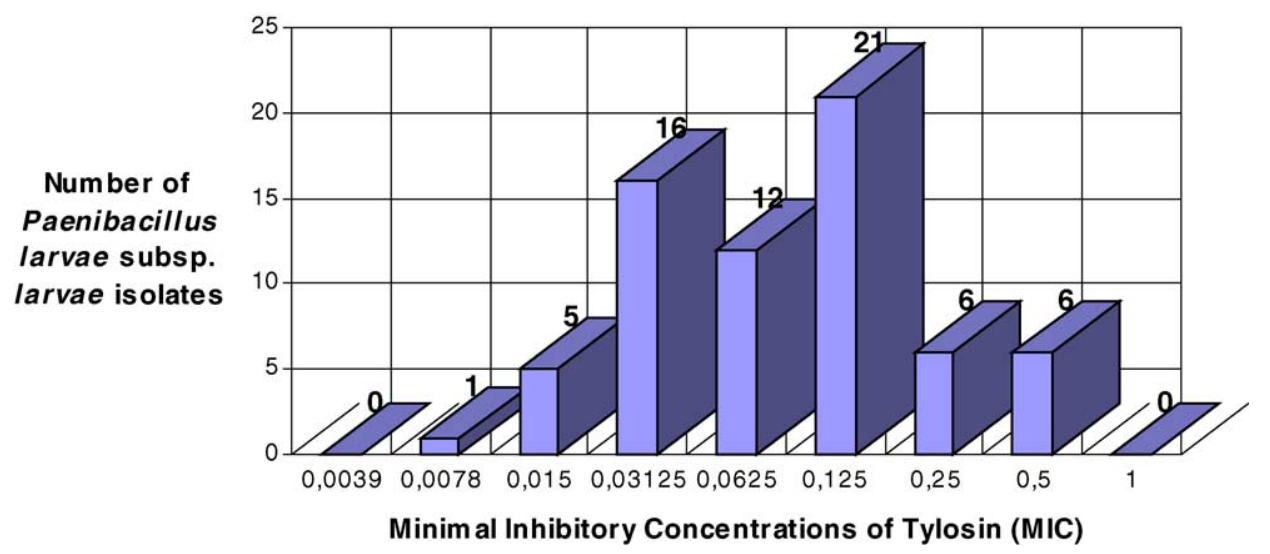

Fig. 1. Frequency of MICs for tylosin between the Paenibacillus larvae subsp. larvae isolates tested.

when testing 67 strains from different geographical origins. These results are in accordance with previous studies on strains from Japan, where MIC values were between 0.025 and $0.1 \mu \mathrm{g} / \mathrm{ml}$ (Okayama et al., 1996).

The National Committee for Clinical Laboratory Standards do not provide a standard method for determining MIC values for P.l. larvae (NCCLS, 1999), nor have breakpoints for antibiotic resistance been established. The values of MIC obtained using MYPGP agar for reference strain of $P$. aeruginosa ATCC 27853 MIC $>32$, S. aureus ATCC 29213 MIC $=2$ and E. coli ATCC 29922 MIC $>32$ are within the acceptable limits for quality control strains, being $>32$, between 0.5 and $4 \mu \mathrm{g} / \mathrm{ml}$ and $>32$, respectively. Isolates could be considered as susceptible when their MICs were $\leq 8$, intermediate for MICs of 16 and resistant for MICs $\geq 32$, as suggested for tylmicosin (NCCLS, 1999) or resistant when their MICs were $\leq 4$ as considered for many antibiotics (Gales et al., 2001). Based upon the results of the present study, there are not any P.l. larvae resistant or intermediate strains for tylosin. Further studies that include resistant and/or intermediate P.l. larvae strains are needed to corroborate this hypothesis, but until present there is not tylosin resistance reported for this species.

\subsection{Field experiments}

In the first field experiment, three out of five AFBinoculated control colonies showed symptoms 60 days after inoculation, and 150 days after inoculation, all colonies showed clinical signs ranging from level 1 to level 6. On the other hand, the colonies treated with tylosin showed no symptoms at all. The results from the first field experiment showed that the disease was controlled in all of the treated colonies and no recurrence of the disease was observed after the end of the experiment by using six candies of $250 \mathrm{mg}$ tylosin (Table 2 and Fig. 2).

During the second field experiment two colonies treated with tylosin showed symptoms 90 days after inoculation (level 1). One colony recovered 120 days after inoculation (level 0) and the other remained with less than three larvae affected (level 1) (Table 3). One of the AFB-inoculated controls showed symptoms after 30 days. After 90 days, all AFB-inoculated controls showed clinical signs of the disease and the infection increased throughout the end of the experiment (ranging from level 1 to level 6) (Table 3). The results from the second field experiment showed that the disease was controlled in $80 \%$ of the treated colonies and no recurrence of the disease was observed after the end of the experiment by using one candy of $750 \mathrm{mg}$ of tylosin (Table 3 and Fig. 2).

In the third field experiment, after 90 and 120 days of the infection, in the tylosin treatments, no AFB diseased larvae were found, and after 150 days one colony exhibited two larvae with clinical symptoms of AFB (level 1). The AFB-inoculated controls showed clinical signs in three of them 60 days after infection (level 1). Two of them died after 90 and 120 days, respectively (level 6) (Table 4 and Fig. 2). 
Table 2

Clinical symptoms of AFB and amount of healthy brood and adult bees per colony and inspection date during the first field experiment starting in March 29, 2000

\begin{tabular}{|c|c|c|c|c|c|c|c|c|c|c|c|c|c|c|c|c|}
\hline \multirow[t]{2}{*}{ Treatment } & \multirow{2}{*}{$\begin{array}{l}\text { Colony } \\
\text { number }\end{array}$} & \multicolumn{3}{|c|}{ May 29} & \multicolumn{3}{|c|}{ July 11} & \multicolumn{3}{|c|}{ August 11} & \multicolumn{3}{|c|}{ September 11} & \multicolumn{3}{|c|}{ October 17} \\
\hline & & Brood & Bees & $\overline{\mathrm{AFB}}$ & Brood & Bees & $\mathrm{AFB}$ & Brood & Bees & $\mathrm{AFB}$ & Brood & Bees & $\mathrm{AFB}$ & Brood & Bees & AFB \\
\hline Control & 118 & 2 & 3 & 0 & 2 & 4 & 1 & 2 & 3 & 2 & 3 & 4 & 4 & 4 & 5 & 4 \\
\hline Control & 107 & 2 & 3 & 0 & 1 & 2 & 1 & 0 & 0 & 6 & 0 & 0 & 6 & 0 & 0 & 6 \\
\hline Control & 144 & 2 & 3 & 0 & 2 & 4 & 1 & 2 & 3 & 0 & 2 & 3 & 5 & 2 & 3 & 5 \\
\hline Control & 71 & 2 & 4 & 0 & 2 & 3 & 0 & 3 & 4 & 0 & 3 & 4 & 0 & 5 & 5 & 1 \\
\hline Control & 102 & 2 & 3 & 0 & 1 & 3 & 0 & 2 & 3 & 0 & 2 & 3 & 5 & 0 & 0 & 6 \\
\hline Tylosin & 42 & 2 & 4 & 0 & 2 & 4 & 0 & 2 & 2 & 0 & 3 & 4 & 0 & 4 & 5 & 0 \\
\hline Tylosin & 111 & 2 & 4 & 0 & 2 & 4 & 0 & 2 & 4 & 0 & 3 & 5 & 0 & 4 & 5 & 0 \\
\hline Tylosin & 108 & 2 & 4 & 0 & 2 & 4 & 0 & 2 & 3 & 0 & 4 & 5 & 0 & 8 & 5 & 0 \\
\hline Tylosin & 112 & 2 & 4 & 0 & 2 & 4 & 0 & 2 & 2 & 0 & 3 & 4 & 0 & 4 & 5 & 0 \\
\hline Tylosin & 41 & 2 & 3 & 0 & 2 & 4 & 0 & 3 & 4 & 0 & 4 & 5 & 0 & 3 & 5 & 0 \\
\hline
\end{tabular}

Overall the results were consistent over 3 years of field experiments, in relation to infection level variable, both the Wilcoxon and the Fisher tests showed similar results. The tylosin treated colonies showed significant differences respect compared to the AFB-inoculated controls $(p<0.05)$. Likewise, the analysis of the infection variable in all three experiments together with the Fisher and Mantel Haenszel Chi-square tests gave significant differences for tylosin compared to those of the AFB-inoculated controls (Fisher $p<0.05$; Mantel Haenszel Chisquare $=17,364, p<0.05$ ) (Fig. 2). The result of the analysis of the brood variable in all three experiments under the Fisher test showed significant differences for tylosin compared to the AFBinoculated controls $(p<0.05)$, which confirms the high effectiveness of tylosin. The analysis for the adult

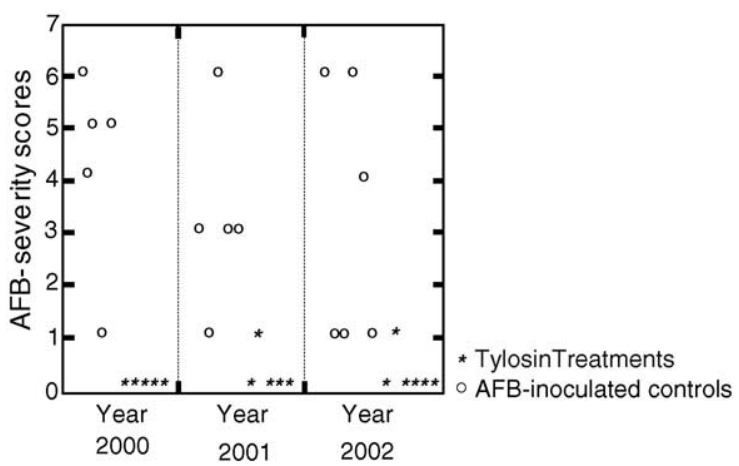

Fig. 2. Severity scores of larvae with AFB-clinical symptoms in tylosin treated and control colonies at the last inspection date during 2000, 2001 and 2002 field experiments. bee variable in all three experiments under the Fisher test showed no significant differences between tylosin and the AFB-inoculated controls $(p>0.05)$. The reason for this could lay in the fact that during the autumn-winter season workers show an increase in lifespan associated with the decrease in the queen's egg laying capabilities. Thus, the disease had no noticeable effects on adults throughout the experiments.

Our results agree with publication data from other researchers about the effectiveness of tylosin for controlling clinical symptoms of AFB. Our previous studies (Alippi et al., 1999) demonstrated the efficacy of tylosin to control AFB by using a formulation of $1500 \mathrm{mg}$ a.i. of tylosin tartrate applied in extender patties or in paper pack in suppressing AFB clinical signs after 1 year after treatment. Peng et al. (1996) found that dosages of 100 and $200 \mathrm{mg}$ of tylosin protected the colonies for 3 and 4 weeks, respectively, but an additional feeding of tylosin at 100, 200, 400 and $800 \mathrm{mg}$ doses can eliminate the signs of infection for an additional 3-week period. Peng et al. (1996) also noticed that bees were reluctant to accept $800 \mathrm{mg}$ tylosin/7 g sugar dose, taking more than 4 weeks for its consumption. In our study bees took less than 21 days to consume $750 \mathrm{mg}$ tylosin tartrate supplied with syrup, probably due to the addition of raspberry essence to improve the taste. Elzen et al. (2002a,b) working with colonies with different levels of infection with oxytetracycline-resistant AFB from a commercial apiary managed to control the infection in 15 and 45 days, respectively, by sprinkling 200 and $400 \mathrm{mg}$ powdered tylosin tartrate. No re-infection was 
Table 3

Clinical symptoms of AFB and amount of healthy brood and adult bees per colony and inspection date during the second field experiment starting in April 13, 2001

\begin{tabular}{|c|c|c|c|c|c|c|c|c|c|c|c|c|c|}
\hline \multirow[t]{2}{*}{ Treatment } & \multirow{2}{*}{$\begin{array}{l}\text { Colony } \\
\text { number }\end{array}$} & \multicolumn{3}{|c|}{ May 13} & \multicolumn{3}{|c|}{ June 10} & \multicolumn{3}{|l|}{ July 8} & \multicolumn{3}{|c|}{ August 5} \\
\hline & & Brood & Bees & AFB & Brood & Bees & AFB & Brood & Bees & AFB & Brood & Bees & AFB \\
\hline Control & $16 \mathrm{D}$ & 1 & 2 & 0 & 1 & 2 & 1 & 2 & 2 & 3 & 1 & 2 & 3 \\
\hline Control & $10 \mathrm{D}$ & 1 & 3 & 0 & 2 & 3 & 0 & 2 & 3 & 1 & 2 & 3 & 1 \\
\hline Control & $14 \mathrm{D}$ & 2 & 3 & 3 & 2 & 3 & 4 & 2 & 2 & 5 & 0 & 0 & 6 \\
\hline Control & $17 \mathrm{D}$ & 2 & 3 & 0 & 2 & 3 & 2 & 2 & 3 & 3 & 2 & 4 & 3 \\
\hline Control & $4 \mathrm{D}$ & 2 & 3 & 0 & 2 & 3 & 1 & 2 & 3 & 2 & 2 & 4 & 3 \\
\hline Tylosin & $3 \mathrm{E}$ & 2 & 3 & 0 & 2 & 3 & 0 & 2 & 3 & 0 & 2 & 3 & 0 \\
\hline Tylosin & $5 \mathrm{E}$ & 2 & 3 & 0 & 1 & 2 & 0 & 2 & 3 & 1 & 2 & 3 & 1 \\
\hline Tylosin & $15 \mathrm{E}$ & 2 & 3 & 0 & 2 & 3 & 0 & 2 & 3 & 1 & 2 & 3 & 0 \\
\hline Tylosin & $6 \mathrm{E}$ & 2 & 3 & 0 & 1 & 2 & 0 & 1 & 2 & 0 & 1 & 2 & 0 \\
\hline Tylosin & $12 \mathrm{E}$ & 2 & 3 & 0 & 2 & 3 & 0 & 2 & 3 & 0 & 2 & 3 & 0 \\
\hline
\end{tabular}

observed 7 months after treatment at both doses, while with doses of $100 \mathrm{mg}$ colonies showed clinical signs of the disease after 3 weeks. In another trial, Elzen et al. (2002a,b) demonstrated that a total dose of $600 \mathrm{mg}$ tylosin over 3 weeks applied as a dust in a powered sugar mixture effectively controls AFB during 3 months, the authors also tested a greasy patty method of application with an equivalent weekly tylosin dosage and found that the method was also effective. However, in all colonies treated with patties bee populations were significantly reduced due to the invasion and proliferation of the small hive beetle Aethina tumida that consume the food sources of a colony, including a greasy patty.

Regarding the form of application and the doses of tylosin used in our study, no significant differences were found among our three experiments $(p<0.005)$, but taking into account that tylosin is converted into desmycosin that could remain stable in honey over 9 months (Kochanski, 2004a,b) we suggest to use a single dose of $750 \mathrm{mg}$ and also in autumn treatment to prevent persistent residues in honey. Applications in syrup are not convenient because it is stored directly by the bees, and any applications during the nectar flow when honey is being stored should be avoided.

Nevertheless, the results obtained from Kochanski (2004b) were from honeys prepared by adding tylosin under laboratory conditions. Further studies are needed to determine the fate of tylosin and desmycosin residues in honey and royal jelly under field conditions at the recommended doses for field trials, and also the disposition profile of tylosin and desmycosin among honeybees, larvae and pupae for understanding its pharmacokinetics in bee colonies.

Table 4

Clinical symptoms of AFB and amount of healthy brood and adult bees per colony and inspection date during the first field experiment starting in May 22, 2002

\begin{tabular}{|c|c|c|c|c|c|c|c|c|c|c|c|c|c|c|c|c|}
\hline \multirow[t]{2}{*}{ Treatment } & \multirow{2}{*}{$\begin{array}{l}\text { Colony } \\
\text { number }\end{array}$} & \multicolumn{3}{|c|}{ June 22} & \multicolumn{3}{|l|}{ July 21} & \multicolumn{3}{|c|}{ August 14} & \multicolumn{3}{|c|}{ September 18} & \multicolumn{3}{|c|}{ October 20} \\
\hline & & Brood & Bees & AFB & Brood & Bees & AFB & Brood & Bees & AFB & Brood & Bees & AFB & Brood & Bees & AFB \\
\hline Control & $4 \mathrm{C}$ & 2 & 3 & 1 & 2 & 3 & 1 & 2 & 2 & 1 & 1 & 2 & 5 & 0 & 0 & 6 \\
\hline Control & $11 \mathrm{C}$ & 3 & 2 & 0 & 2 & 3 & 0 & 2 & 3 & 0 & 2 & 3 & 0 & 3 & 5 & 1 \\
\hline Control & $14 \mathrm{C}$ & 2 & 3 & 0 & 1 & 3 & 0 & 2 & 3 & 0 & 2 & 3 & 0 & 3 & 4 & 1 \\
\hline Control & $3 \mathrm{C}$ & 2 & 3 & 2 & 2 & 3 & 3 & 1 & 2 & 5 & 0 & 0 & 6 & 0 & 0 & 6 \\
\hline Control & $8 \mathrm{C}$ & 2 & 3 & 1 & 2 & 3 & 2 & 2 & 3 & 1 & 2 & 3 & 3 & 2 & 2 & 4 \\
\hline Control & $9 \mathrm{C}$ & 2 & 4 & 1 & 2 & 3 & 0 & 2 & 3 & 0 & 2 & 3 & 0 & 4 & 4 & 1 \\
\hline Tylosin & $41 \mathrm{~A}$ & 2 & 3 & 0 & 2 & 3 & 0 & 2 & 3 & 0 & 2 & 2 & 0 & 2 & 3 & 0 \\
\hline Tylosin & $30 \mathrm{~A}$ & 2 & 3 & 0 & 1 & 3 & 0 & 1 & 2 & 0 & 1 & 2 & 0 & 2 & 3 & 1 \\
\hline Tylosin & $2 \mathrm{~A}$ & 2 & 3 & 0 & 1 & 3 & 0 & 2 & 2 & 0 & 1 & 2 & 0 & 2 & 2 & 0 \\
\hline Tylosin & $5 \mathrm{~A}$ & 2 & 3 & 0 & 1 & 3 & 0 & 1 & 3 & 0 & 2 & 3 & 0 & 2 & 3 & 0 \\
\hline Tylosin & $7 \mathrm{~A}$ & 2 & 4 & 0 & 2 & 3 & 0 & 1 & 3 & 0 & 2 & 2 & 0 & 2 & 3 & 0 \\
\hline Tylosin & $17 \mathrm{~A}$ & 2 & 3 & 0 & 2 & 3 & 0 & 2 & 3 & 0 & 2 & 3 & 0 & 3 & 3 & 0 \\
\hline
\end{tabular}




\section{Acknowledgments}

This research was supported by CIC (Comisión de Investigaciones Científicas de la Provincia de Buenos Aires, Argentina). AMA and MRD are Career Investigators of CIC and FJR is a recipient of a scholarship from CONICET, Argentina.

The authors are grateful to $S$. Dimenna for technical assistance in laboratory and field studies and to Esanco Laboratory, Buenos Aires, Argentina for providing the antibiotic tylosin used for field studies.

\section{References}

Alippi, A.M., 1994. Sensibilidad in vitro de Bacillus larvae frente a diferentes agentes antimicrobianos. Vida Apícola 66, 20-24.

Alippi, A.M., 1995. Detection of Bacillus larvae spores in Argentinian honeys by using a semi-selective medium. Microbiol. SEM 11, 343-350.

Alippi, A.M., 2000. Is Terramicyn ${ }^{\circledR}$ losing its effectiveness against AFB? The Argentinian experience. Bee Biz 11, 27-29.

Alippi, A.M., Aguilar, O.M., 1998. Characterization of isolates of Paenibacillus larvae subsp. larvae from diverse geographical origin by the polymerase chain reaction and box primers. J. Invertebr. Pathol. 72, 21-27.

Alippi, A.M., Albo, G.N., Leniz, D., Rivera, I., Zanelli, M.L., Roca, A.E., 1999. Comparative study of tylosin, erythromycin and oxytetracycline to control American Foulbrood of honeybees. J. Apic. Res. 38, 149-158.

Alippi, A.M., Reynaldi, F.J., López, A.C., De Giusti, M.R., Aguilar, O.M., 2004. Molecular epidemiology of Paenibacillus larvae larvae and incidence of American Foulbrood in Argentinean honeys from Buenos Aires Province. J. Apic. Res. 43, 135-143.

Colter, D., 2000. Antibiotic Resistant American FoulBrood, Alberta Bee News February 4.

Dingman, D.W., Stahly, D.P., 1983. Medium promoting sporulation of Bacillus larvae and metabolism of medium components. Appl. Environ. Microbiol. 46, 860-869.

Elzen, P., Westervelt, D., Causey, D., Rivera, R., Baxter, J., Fedlaufer, M., 2002a. Control of oxytetracicline-resistant American Foulbrood with tylosin and its toxicity to honey bees (Apis mellifera). J. Apic. Res. 41, 97-100.

Elzen, P., Westervelt, D., Causey, D., Ellis, J., Hepburn, H.R., Neumann, P., 2002b. Method of application of tylosin, an antibiotic for American Foulbrood control, with effects on small hive beetle (Coleoptera: Nitidulidae) populations. J. Econ. Entomol. 95, 1119-1122.

Evans, J.D., 2003. Diverse origins of tetracycline resistance en the honey bee bacterial pathogen Paenibacillus larvae. J. Invertebr. Pathol. 83, 46-50.

Gales, A.C., Reis, A.O., Jones, R.N., 2001. Contemporary assestment of antimicrobial susceptibility testing methods for polymyxin B and colist. Review of available interpretative criteria quality control guidelines. J. Clin. Microbiol. 39, 183-190.
Heyndrickx, M., Vandemeulebroecke, K., Hoste, B., Janssen, P., Kersters, K., De, V.P., Logan, N.A., Ali, N., Berkeley, R.C.W., 1996. Reclassification of Paenibacillus (formerly Bacillus) pulvifaciens (Nakamura 1984). Ash et al. a later subjective synonym of Paenibacillus (formerly Bacillus) larvae (White 1906) Ash et al. as a subspecies of $P$. larvae, with emended descriptions of $P$. larvae as $P$. larvae subsp. larvae and P. larvae subsp. pulvifaciens. Int. J. Sys. Bacteriol. 46, 270-279.

Hitchcock, J.D., Moffett, J.O., Lacket, J.J., Elliot, J.R., 1970. Tylosin for control American Foulbrood disease in honeybees. J. Econ. Entomol. 63, 204-207.

Kochanski, J., 2004a. Evaluation of purification schemes in the determination of tylosin in honey using high performance liquid chromatography. J. Apic. Res. 43, 60-64.

Kochanski, J., 2004b. Degradation of tylosin residues in honey. J. Apic. Res. 43, 65-68.

Kochanski, J., Knox, D.A., Feldlaufer, M., Pettis, J.S., 2001. Screening alternatives antibiotics against oxytetracycline-susceptible and resistant Paenibacillus larvae. Apidologie 32, 215-222.

Matheson, A., Reid, M., 1992. Strategies for the prevention and control of American Foulbrood. Am. Bee. J. 132, 399402.Matheson, A., Reid, M., 1992. Strategies for the prevention and control of American Foulbrood. Am. Bee. J. 133, 471475.Matheson, A., Reid, M., 1992. Strategies for the prevention and control of American Foulbrood. Am. Bee. J. 143, 534-547.

Miyagi, T., Peng, C.Y.S., Chuang, R.Y., Mussen, E.C., Spivak, M.S., Doi, R.H., 2000. Verification of oxytetraciclina-resistant American Foulbrood pathogen Paenibacillus larvae in the United States. J. Invertebr. Pathol. 75, 95-96.

Moffett, J.O., Hitchcock, J.D., Lackett, J.J., Elliot, J.R., 1970. Evaluation of some new compounds in controlling American Foulbrood. J. Apic. Res. 9, 39-44.

National Committee for Clinical Laboratory Standards, 1999. Performance standards for antimicrobial disk and dilution susceptibility tests for bacteria isolated from animals. Approbed Standard, NCCLS Document M31-A, National Committee for Clinical Laboratory Standards, Wayne, PA, USA.

Okayama, A., Sakowaga, T., Nakajima, C., Hayama, T., 1996. Biological properties and antibiotic susceptibility of Bacillus larvae originated from American Foulbrood of honeybee in Japan. J. Vet. Med. Sci. 58, 439-441.

Peng, Y.S., Mussen, E., Fong, A., Montague, M.A., Tyler, T., 1992. Effects of chlortetracycline on honey bee worker larvae reared in vitro. J. Invertebr. Pathol. 60, 127-133.

Peng, Y.S., Mussen, E., Fong, A., Cheng, P., Wong, G., Montague, M.A., 1996. Laboratory and field studies on the effects of the antibiotic tylosin on honey bee Apis mellifera L (Hymenoptera: Apidae). Development and prevention of American Foulbrood disease. J. Invertebr. Pathol. 67, 65-71.

Shimanuki, H., 1990. Bacteria. In: Morse, R.A., Nowogrodzki, R. (Eds.), Honey Bee Pests, Predators and Diseases. second ed. Cornell University Press, USA, pp. 27-47.

Spivak, M., Reuter, G.S., 2001. Resistance to American Foulbrood disease by honey bee colonies Apis mellifera bred for hygienic behavior. Apidologie 32, 555-565.

White, G.F., 1920. American Foulbrood, United States Department of Agriculture, Bulletin No. 809, 46 pp. 